\title{
A case study of consumer preferences towards different brands of palm oil in Shah Alam, Selangor, Malaysia
}

\author{
${ }^{1}$ Ibrahim, M.I.S,,${ }^{1,}$ Abdul Fatah, F. and ${ }^{2}$ Saili, A.R. \\ ${ }^{1}$ Faculty of Plantation and Agrotechnology, Universiti Teknologi MARA (UiTM), Cawangan Melaka \\ Kampus Jasin, 77300 Merlimau, Melaka, Malaysia \\ ${ }^{2}$ Faculty of Plantation and Agrotechnology, Universiti Teknologi MARA (UiTM), Cawangan Sarawak, \\ Jalan Meranek, 94300 Kota Samarahan, Sarawak, Malaysia
}

\begin{abstract}
Article history:
Received: 22 July 2020

Received in revised form: 19

November 2020

Accepted: 11 December 2020

Available Online: 20

December 2020
\end{abstract}

Keywords:

Consumer preferences,

Palm oil,

Awareness,

Quality,

Marketing

DOI:

https://doi.org/10.26656/fr.2017.4(S5).012

\begin{abstract}
The palm oil industry has played a vital role in the economic development of Malaysia and the economic expansion in developing countries primarily drove the growth in palm oil consumption. However, consumer preference towards palm oil products is changing due to the population increase, rapid urbanisation, rising income levels, development of communication tools, and negative campaign towards palm oil. Hence, this study was conducted to identify consumers' preferences towards palm oil to understand this predicament further. In this study, the data were obtained from 107 respondents through convenient sampling from different supermarkets in Shah Alam, Selangor. Moreover, factors such as socioeconomic, marketing, and non-marketing factors were investigated, which employed descriptive analysis, factor analysis, and multiple regression analysis. The results showed that majority of the respondents were Malay females, married, and were in the age range between 31 and 40 years old. Most of these respondents completed secondary schools and were now working in public and private sectors with a monthly income between RM2001 and RM3000. It was found that most of the respondents purchased the bottled "Saji" brand palm oil at least once a month, and advertising was the primary source of brand information for the respondents. Furthermore, the multiple regression analysis of marketing factors revealed that product and price were the most significant factors that influenced consumer preferences towards palm oil. Meanwhile, non-marketing factors indicated that the quality of products, as well as advertising or campaign, were the significant determinants which affected consumer preferences towards palm oil. On that basis, this article proposed a few recommendations to enhance consumer preferences towards palm oil in the future.
\end{abstract}

\section{Introduction}

The total global population is expected to exceed 7.71 billion people, which will continuously grow (World Population Review, 2019), and at the same time, the Malaysian population is recorded to reach over 32,396,203 people. Given the growing global population, improving the economic condition of a particular country has enhanced its urbanisation. This rapid urbanisation accelerates consumers' dietary transition as they prefer higher-quality food and are willing to pay for nutritious as well as healthy products (Regmi and Dyck, 2001). Moreover, the growth of income changed the food landscape in recent years as consumers were earning more sizeable disposable incomes (Cirera and Masset, 2010), which was closely related to an improved quality of life and economic conditions. In other words, consumers were now shifting their diet towards better food quality and nutrient content in their diets (Huang and Gale, 2009).

The vast existence of newer vegetable oils entering the market developed speculations on the quality and safety of the vegetable oils (Sarwade, 2011). Moreover, the producers tend to classify their products' information, and this liquidity of information influenced the consumer preference towards vegetable oil (Lam et al., 2018). Furthermore, due to the extensive usage of vegetable oil for cooking or garnishing food, its consumption was related to the consumers' safety concern. As a result, consumers increased the demand for information on the quality and safety of the product, 
which may ultimately influence their preference towards the item (Lam et al., 2018). Additionally, they begin to develop their preferences towards different vegetable oils available in the market after possessing higher awareness as well as knowledge on the product (Nondzor et al., 2015).

Malaysia is well-known for its oil palm tree plantation and palm oil production, which is a form of vegetable oil (MPOC, 2017). In tropical and warm climates like in Africa and Asia, palm trees are commonly found where various parts its fruits are used to obtain the palm oil and palm kernel oil, which are edible plant oils. The kernel seed, which is the inner part of the tree produces the palm kernel oil (Poku, 2002), and the pulp of the fruit, which is the outer part of the tree provides the palm oil (Elaeis guineensis). Specifically, the mesocarp of the oil palm fruits bears the palm oil, which possesses a balance of saturated (mainly palmitic) fatty acids and unsaturated (mainly oleic). Furthermore, for thousands of years, palm oil is utilised in multiple food preparation with approximately $80 \%$ of its products used for comestible application (Basiron, 2007). Currently, this vegetable oil is vastly consumed on a global scale as a versatile as well as an economical raw material, which is used in edible as well as inedible products (Zion Market Research, 2017). Moreover, in terms of the palm oil's physical properties, it is relatively identical to animal fats such as tallow and lard, which makes it an excellent fat substitute from meat products such as sausages and meat patties (O'Brien, 2009). Notably, palm oil varies profoundly from palm kernel oil (PKO)'s composition and properties, in which PKO possess a higher lauric acid content with a sharper melting profile. Thus, making it favourable for confectioneries as well as other speciality fats (Nor Lida Habi et al., 2017).

The oil palm industry has played a vital role in the development of Malaysia and continues to make a significant contribution to the national economy (Nordin et al., 2012; Wan Ariffin and Abdul Fatah, 2018). Compared to other crops, oil palm was found as the most productive crop with five times higher oil production (Seng and Ahmad, 2017), thus played a critical role in the Malaysian palm oil industry. However, other vegetable oils, such as olive and coconut oil, still garnered a significant position in the local market (Seng and Ahmad, 2017). The growth in palm oil consumption is primarily driven by the economic expansion in developing countries, in which its importance in the individuals' daily diet was well recognised and became a vital part of their daily food intake (Gunstone, 2002). Furthermore, the demand for palm oil proliferated with the increase in human population and improved standard of living (Dhinesh and Venkateshwaran, 2010). Moreover, this demand for consumption was further stimulated by the rapid urbanisation, rising income levels, and development of communication tools in various countries (Nondzor et al., 2015). Hence, with the current technological growth and an increasing number of producers, consumers were subsequently exposed to a variety of vegetable oils including palm oil which claimed to have the best benefit (Isik and Yasar, 2015).

However, the consumption of palm oil posed a growing concern for individuals' health. Specifically, the research reviewed the link between palm oil consumption and the indirect cardiovascular effect, like altering cholesterol levels (Imosi et al., 2015; Mat Dian et al., 2017; Sophia Resheeqa et al., 2018), which was caused by trans-fatty acids derived from hydrogenated commodities like palm oil. Moreover, a crucial precursor of cardiovascular diseases (CVD) responsible for 31\% of the global fatality (Holub, 2002) was indicated by elevated cholesterol levels, which was associated with the saturated fatty acid over consumption (Page et al., 1957; Blacket et al., 1965). Contrastingly, Sophia Rasheeqa et al. (2018) indicated that there was no tangible link between palm oil consumption and the mortality risk from CVD, such as coronary heart disease and stroke. Similarly, a study by Imosi et al. (2015) revealed that when incorporated in a balanced diet, the palm oil did not accumulate the risk for cardiovascular disease. Nevertheless, the potential detrimental impact of ingesting foods high in trans-fatty acids, which was derived from partially hydrogenated oils elevated the consumers' full cognisance towards this issue.

Furthermore, the oil palm sector suffered numerous issues that require extensive considerations, which comprised of stagnating yields, the industry's fragmentation, and the transformation of tropical rainforest as well as peatlands in several South-east Asian regions (Murphy, 2014). It was claimed that the palm oil industry posed environmental impacts as well as degradations, such as deforestation, biodiversity loss, and net greenhouse gas (GHG) emissions, which were caused by the oil palm cultivation development (European Commision, 2018). Hence, the European Union (EU) prohibited the sector from importing palm oil for biofuels, in which this resolution was developed and agreed upon after obtaining favourable votes by the Members of the European Parliament (MEP). Specifically, the resolution revealed that the primary reason and driving force of deforestation was oil palm cultivation (MPOC, 2017). Incidentally, it was found that in $2018,16,487,556$ tonnes of palm oil were globally 
exported by Malaysia, which was the major exporter of palm, albeit this global export mainly to the European Union (EU) has perennially decreased (MPOB, 2018).

Given these circumstances, palm oil was situated at the intersection between the economic, health, and environmental policy interests (Keogh-Brown et al., 2019), which made it challenging and complicated for the prerogative of consumers to select among the cornucopia of vegetable oils (Isik and Yasar, 2015) especially palm oil. Mass media were widely used to provide information to larger populations through uses of existing media, in which the health and benefits of vegetable oils were broadcasted to consumers (Wakefield et al., 2010). Hence, consumers were increasingly curious about their food purchases and consumption that affected their daily life and used communication platforms to obtain information due to the increased concern on their health (Shiratori and Kinsey, 2011).

Consumer preferences were defined as the subjective tastes of individual consumers, which could be measured by their satisfaction with a specific item, compared to other opportunity costs available (Weedmark, 2018). The consumers' preferences were not necessarily contained within their field of economics but may be influenced by other factors (Nondzor et al., 2015). Notably, given that preferences were an indicator for consumer demand, consumer choices were not always determined by their preferences alone (Anojan and Subaskaran, 2015). Consumers often had product alternatives or options before making choices and would look into the best combination of product attributes that meet their needs (Voicu, 2013). Additionally, consumers may be influenced by current issues, such as the resolution that prohibited palm oil from entering Europe, which was imposed by the EU (MPOC, 2017), which hindered the development of the oil palm industry and potentially diminished the consumers' confidence towards palm oil consumption (MPOC, 2017).

The marketing strategy that may affect consumer preferences comprises the 4P's of marketing which is price, place, product, and promotion. Specifically, the price determined how much a product or service costs, while the frequency of purchase was affected by several factors with the price being the primary factor (Ohen et al., 2014). Furthermore, other factors include packaging, quality, availability, awareness, and advertising. Notably, the packaging was a significant variable for consumer preference in palm oil and its brands (Hasan and Khan, 2009), in which a well-developed packaging helped producers to grab the consumers' interest (Dhinesh and Venkateshwaran, 2010). Moreover, the quality was a crucial aspect of any product as it determined the lifespan of a product, which was more vital in the case of edible oil due to its consumption factor and association with an individual's wellbeing (Prema, 2013). In the case of product availability, a study revealed that the primary factor considered in purchasing was the accessibility of the product (Swamy et al., 2012), which included reasonable price, obtainability at different locations, various size and forms of packaging (Hasan and Khan, 2009).

In the context of edible oil, awareness can be related to a consumer's understanding of the benefit of vegetable oil on their health. A study found that consumers prefer branded products as they believed the quality was better and assured by the reputed companies (Jain and Meenakshi, 2012). Additionally, the consumers' awareness of the environment was also seen as the reason for their choice of products that generally benefited their health, safety, and the environment (Gupta and Jain, 2014). A study found that the food industry was one of the crucial players in the field of advertising that formed consumer preferences towards a product (Hastings, 2003). Hence, to add value to these products, advertising was commonly done in the marketing process that highlighted the products' brand (Pahwa, 2019). To date, studies have analysed consumer preferences on vegetable oil, such as olive oil, canola oil, and coconut oil in other countries (Jain and Meenakshi, 2012; Prema, 2013), though, limited studies focused on palm oil, even by the product's manufacturing countries. Therefore, this study explores the consumer preferences towards vegetable oil, mainly palm oil in Malaysia. The objective of this study was to analyse and identify the factors influencing consumer preference towards palm oil in Shah Alam, Selangor, Malaysia.

\section{Materials and methods}

\subsection{Location of study}

Statistics revealed that around 481,654 people were residing in Shah Alam, a capital city district of Selangor (GeoNames, 2017). Hence, the study was conducted in Shah Alam, which was purposely selected to identify factors that influences consumer preference towards palm oil. The respondents were selected from five types of dominant hypermarket competitors available in Shah Alam, which included Carrefour, Econsave, Giant, Mydin, and Tesco (Hassan and Rahman, 2012). In conducting this study, random samples of respondents were selected from different locations in Shah Alam, namely, Setia Alam, Padang Jawa, Bukit Jelutong, and Seksyen 7, in which the dominant hypermarkets exist. Lastly, the questionnaire was distributed to the selected respondents between July and September 2019. 


\subsection{Sampling method}

Due to its straightforward, rapid, and cost-effective approach, the non-probability sampling method was used to choose the units for inclusion in a sample vis-à-vis the probability sampling method (Farrokhi and MahmoudiHamidabad, 2012). Specifically, there were several types of non-probability sampling, such as quota sampling, convenience sampling, purposive sampling, selfselection sampling, and snowball sampling (Battaglia, 2011). In this study, a convenience sampling technique was used to collect the required information and data due to its practicality and feasibility (Alvi, 2016). The vital significance in convenience sampling was the simplicity to locate or recruit potential participants, which were chosen based on the researchers' convenience instead of using a formal sample design (Baker et al. 2013).

Furthermore, researchers acquired an actual number of respondents, which expanded fewer times and resources by using convenience sampling. This convenience sample was indicated by the units' designated inclusion in the sample that possessed the highest accessibility (Cooper and Schindler, 2008). Moreover, this type of sampling technique was chosen due to the inadequately defined population that was suitable to be used as samples, which were selected based on the subjective judgement of the researcher (Alvi, 2016). Additionally, members of the target population were chosen according to specific practical criteria, such as easy accessibility, geographical proximity, availability at a given time, or the willingness to participate (Etikan et al., 2016).

The convenience sampling was presented in various concepts like a panel of volunteers (Couper and Bosnjak 2010), river samples (Olivier 2011), malls or store intercepts (Sarstedt and Mooi, 2014), and snowball samples (Naderifar et al., 2017). In this study, convenience sampling through the store-intercept approach was utilised to choose the respondents due to the practical challenges in discerning the target population. To obtain data from consumers, a selfadministered survey instrument was used, in which both approaches revealed multiple advantages that ultimately determined the method selection. To reduce interview bias, reduced number of staff to distribute and collect completed questionnaires, convenience sampling was more cost-effective, allowed rapid administration, and economically obtained an extensive number of respondents as compared to random or systematic techniques (Cooper and Schindler, 2008).

Furthermore, retail food stores that comprised various brands of palm oil and other vegetable oils sold were selected as the location for the surveys, which included five types of stores, such as hypermarkets or supermarkets. This idea established reasonable variability on the participant households' relevant characteristics, such as income, education or occupation, and store characteristics (presence/absence of a designated palm oil section). The vital purchasers of palm oil for their household and aged 18 years or older were selected as the targeted consumers for the questionnaire. From a total of 150 questionnaires, a sum of 102 questionnaires was complete and useable, which yielded a response rate of $68 \%$.

\subsection{Data analysis}

The data for this study were obtained from the questionnaire, which consisted of five main sections where the respondents were asked concerning: the background information such as age, gender, education, income, occupation and race (Section A); purchasing information, such as brand purchase, purchase purpose, purchase frequency, packaging type and size, as well as a source of information (Section B); consumer preferences of palm oil, which included the probable characteristics considered by the consumers when purchasing palm oil (Section C); marketing factors affecting palm oil preference including price, place, promotion and product, as well as other factors affecting consumer preference (Section D); and lastly on quality, availability, awareness, and advertising (Section E).

By utilising a 5-point Likert scale (with one equals to disagree strongly and five equals to agree strongly), consumers were asked to score items that measured their preferences towards palm oil in Section B and the factors affecting consumer preferences in Section C, D, and E. Next, the answers obtained from the questionnaire were used to create data that will be transformed into a form that was more suitable and easier to understand. Additionally, the questions were extracted into small sets of factors by using principal component analysis and further analysed using multiple regression analysis to identify the significant factors that affected consumer preferences towards palm oil.

\subsection{Statistical method}

To achieve the objective of the study, various statistical tools and techniques, such as reliability test, percentage analysis, frequency analysis, factor analysis, and multiple regression were used to analyse the collected data. The reliability test was used to determine the quality and usefulness of the test. In contrast, the descriptive statistics of frequency analysis, as well as percentage analysis, were used to understand the purchase and consumption pattern of palm oil. Percentage analysis was used to analyse consumer 
preference and purchasing behaviour for palm oil, while, the factor analysis and multiple regression were employed to examine the factors influencing the consumer's decision-making choice for palm oil. Furthermore, to produce a more user-friendly result, the Statistical Package of Social Science (SPSS) and Microsoft Excel were used for the analysis of data.

Regression analysis was used to estimate the relationship among variables with reason and result relation (Uyanik and Guler, 2013), which also allowed researchers to identify the strength that independent variables had on a dependent variable. This analysis determined the extent to which there was a linear relationship between a dependent variable and one or more independent variables (Foley, 2018). Multiple regression was vastly used to determine the relationship between a dependent variable and an independent variable, especially when there were various numbers of independent variables (Leech et al., 2003). Hence, to identify the factors that influence consumer preferences on palm oil, a multiple regression analysis was used in this study with the formula below:

$\mathrm{Y}=\mathrm{A}+\beta_{1} \mathrm{X}_{1}+\beta_{2} \mathrm{X}_{2}+\beta_{3} \mathrm{X}_{3}+\beta_{4} \mathrm{X}_{4}+\ldots \ldots \ldots \ldots \ldots \ldots \beta_{9} \mathrm{X}_{9}$ $+\varepsilon$

Where $\mathrm{Y}$ was a dependent variable, which represented the consumer preferences towards palm oil; A was a constant, B was the coefficient to be estimated; $\mathrm{X}_{1^{-}} \mathrm{X}_{9}$ were independent variables, which comprised price, place, product, promotion, packaging, quality, availability, awareness, and advertising; and $\varepsilon$ was the error term.

\subsubsection{Dependent variable}

\subsubsection{Consumer preferences towards palm oil}

Defined as the degree to which an individual respondent has a greater liking or preference for palm oil over other vegetable oils.

\subsubsection{Independent variables}

\subsubsection{Marketing factors}

These marketing factors comprised the activity, set of institutions, and processes that were used to create, communicate, deliver, and exchange offerings that provided value not only for customers but also clients, partners, and society at large. Lastly, these factors usually involved careful development of suitable price, product, place, and promotion.

\subsubsection{Non-marketing factors}

These factors were defined as other activity, set of institutions, and processes that were used to create, communicate, deliver, and exchange offerings that provided value for not only customers but also clients, partners, and society at large. These factors were not related to the main marketing component of 4P's but rather on factors that may influence consumers to choose palm oil. Moreover, these factors included quality, availability, awareness (including PO campaigns, either positive or negative), and advertising.

\subsection{Conceptual framework}

Based on the existing findings and literature on consumer preferences that were previously discussed, the conceptual framework was formalised as shown in Figure 1.

\section{Results and discussion}

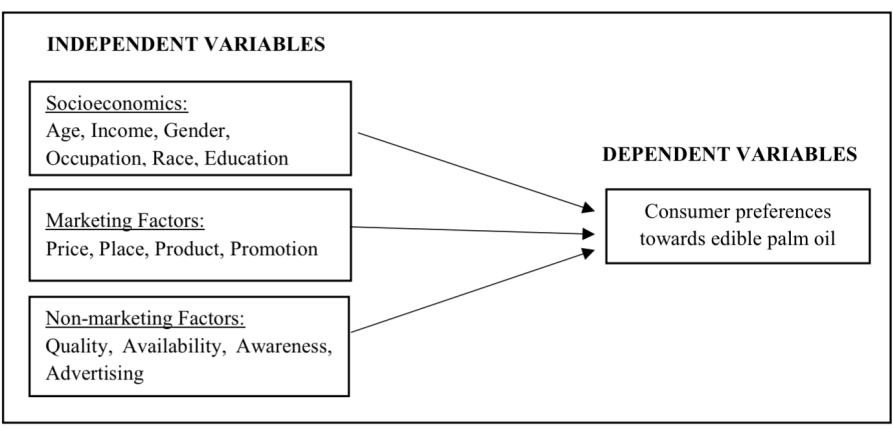

Figure 1. Conceptual Framework illustrates the link between all variables and the theory of consumer preference

\subsection{Demographic characteristics of respondents}

A total of 107 respondents were interviewed in this study. Table 1 displays the summary of demographic variables including age, gender, education, marital status, occupation and income. The results of sociodemographic information showed that majority of the respondents were Malay female $(\mathrm{n}=59,55.1 \%)$, married $(\mathrm{n}=75,70.1 \%)$ and were in the age range of 31 to 40 years old $(\mathrm{n}=33,30.8 \%)$. Most of these respondents received a secondary school education $(n=56,52.3 \%)$. Furthermore, those who earned an income of between RM1001 to RM2000 ( $\mathrm{n}=55,51.4 \%)$ were working in the government sector while those making between RM2001 and RM3000 ( $n=20,18.7 \%)$ were in the private sector. Based on these points, it was observed that these participants were capable of making their own purchasing decision and had the purchasing power to buy palm oil in the market.

\subsection{Consumer purchasing information}

Table 2 shows information regarding consumer purchasing of palm oil in the market. Notably, all 107 respondents were buying PO for their daily usage, either for personal $(n=68,63.6 \%)$ or business usage $(n=39$, $36.4 \%$ ). Additionally, this finding was regardless of their 
Table 1. Socio-demographic of respondents

\begin{tabular}{|c|c|c|c|}
\hline Variables & Characteristics & Frequency (n) & Percentage \\
\hline \multirow{2}{*}{ Gender } & Male & 48 & $44.90 \%$ \\
\hline & Female & 59 & $55.10 \%$ \\
\hline \multirow{5}{*}{ Age } & 20 years old -30 years old & 17 & $15.90 \%$ \\
\hline & 31 years old -40 years old & 33 & $30.80 \%$ \\
\hline & 41 years old - 50 years old & 27 & $25.20 \%$ \\
\hline & 51 years old -60 years old & 20 & $18.70 \%$ \\
\hline & 61 years old -70 years old & 10 & $9.30 \%$ \\
\hline \multirow{3}{*}{ Marital Status } & Single & 32 & $29.90 \%$ \\
\hline & Married & 75 & $70.10 \%$ \\
\hline & Divorced & 0 & $0.00 \%$ \\
\hline \multirow{4}{*}{ Races } & Malay & 76 & $71.00 \%$ \\
\hline & Chinese & 18 & $16.80 \%$ \\
\hline & Indian & 10 & $9.30 \%$ \\
\hline & Others & 3 & $2.80 \%$ \\
\hline \multirow{4}{*}{$\begin{array}{l}\text { Education } \\
\text { Background }\end{array}$} & Primary school & 3 & $2.80 \%$ \\
\hline & Secondary school & 56 & $52.30 \%$ \\
\hline & University & 45 & $42.10 \%$ \\
\hline & Other & 3 & $2.80 \%$ \\
\hline \multirow{3}{*}{ Occupation } & Government sector & 25 & $23.40 \%$ \\
\hline & Private sector & 63 & $58.90 \%$ \\
\hline & Other sector & 19 & $17.80 \%$ \\
\hline \multirow{5}{*}{ Income } & RM000 - RM1000 & 9 & $8.40 \%$ \\
\hline & RM1001 - RM2000 & 55 & $51.40 \%$ \\
\hline & RM2001 - RM3000 & 20 & $18.70 \%$ \\
\hline & RM3001 - RM4000 & 2 & $1.90 \%$ \\
\hline & Above RM4000 & 21 & $19.60 \%$ \\
\hline
\end{tabular}

Table 2. Consumer purchasing information on palm oil among respondents

\begin{tabular}{llcc}
\hline Variables & Characteristics & Frequency (n) & Percentage \\
\hline \multirow{2}{*}{ Purpose of purchase } & Personal usage & 68 & $63.60 \%$ \\
& Business usage & 39 & $36.40 \%$ \\
\hline & Saji & 57 & $53.30 \%$ \\
& Aliff & 17 & $15.90 \%$ \\
Brand of palm oil purchased & Seri Murni & 20 & $18.70 \%$ \\
& Buruh & 4 & $3.70 \%$ \\
& VeSawit & 2 & $1.90 \%$ \\
& Knife & 3 & $2.80 \%$ \\
& Red Eagle & 4 & $3.70 \%$ \\
\hline \multirow{5}{*}{ Frequency of purchase } & Everyday & 3 & $2.80 \%$ \\
& Once in a week & 7 & $6.50 \%$ \\
& Once in two weeks & 37 & $34.60 \%$ \\
& Once in a month & 60 & $56.10 \%$ \\
\hline \multirow{2}{*}{ Type of packaging purchased } & Bottle & 100 & $93.50 \%$ \\
& Packet & 7 & $6.50 \%$ \\
\hline \multirow{5}{*}{ Size of packaging purchased } & 1 kilogram & 13 & $12.10 \%$ \\
& 2 kilogram & 35 & $32.70 \%$ \\
& 3 kilogram & 13 & $12.10 \%$ \\
& 5 kilogram & 31 & $29.00 \%$ \\
& 1 liter & 11 & $10.30 \%$ \\
& 2 liter & 4 & $3.70 \%$ \\
\hline \multirow{5}{*}{ Information access } & Educators & 4 & $3.70 \%$ \\
& Retailer & 20 & $18.70 \%$ \\
& Doctor & 2 & $1.90 \%$ \\
& Past experience & 14 & $13.10 \%$ \\
& Advertisement & 60 & $56.10 \%$ \\
& Friend and Relative & 4 & $3.70 \%$ \\
& Social media & 3 & $2.80 \%$ \\
\hline
\end{tabular}


gender, age, marital status, education background, occupation, and income. Furthermore, this information showed that palm oil was essential in their everyday lives and most respondents chose Saji brand $(\mathrm{n}=57$, $53.3 \%$ ) as the majority of the respondents were Malay individuals, followed by Seri Murni $(\mathrm{n}=20,18.7 \%)$ and Aliff brands $(\mathrm{n}=17,15.9 \%)$. Moreover, most of these respondents purchased palm oil at least once a month (n $=60,56.1 \%)$ and preferred to buy the bottled packaging ( $\mathrm{n}=57,53.3 \%$ ) compared to the packeted packaging ( $\mathrm{n}$ $=100,93.5 \%)$. Additionally, the respondents preferred to buy the 2-kilogram sized packaging $(\mathrm{n}=35,32.7 \%)$ followed by the 5-kilogram sized packaging $(\mathrm{n}=31$, $29 \%)$. Advertising $(n=60,56.1 \%)$ was the main source of information channel where the participants obtained information about the brand through television, magazine, newspaper, and radio.

\subsection{Factor analysis of marketing and other non- marketing factors}

In factor analysis, a total of 51 variables, which comprised of 22 variables on the marketing factors and 29 variables on non-marketing factors were analysed and discussed (Table 3). The Kaiser-Meyer-Olkin (KMO) and Bartlett's test played an important role in accepting the sample's adequacy. Specifically, the KMO's measure of sampling adequacy was used to indicate the proportion of variance in the variables potentially caused by underlying factors (IBM, 2019). Meanwhile, Bartlett's test of sphericity tested the hypothesis that the correlation matrix was an identity matrix, which would indicate that the variables were unrelated and therefore, unsuitable for structure detection (IBM, 2019). The value was considered acceptable for social science studies if the KMO value was more than 0.6 (Tabachnick and Fidell, 2001). Moreover, the value was deemed significant for social science studies if the Barlett's test value was less than 0.5 (IBM, 2019). In this analysis, the KMO value was 0.787 for marketing factors and 0.776 for non-marketing factors, which indicated the data

Table 3. KMO and Bartlett's Test of marketing and nonmarketing factors

KMO and Bartlett's Test of marketing factors

Kaiser-Meyer-Olkin Measure of Sampling

Adequacy

Bartlett's Test of Sphericity Approx. Chi-Square

Df

0.787

1816.376

Sig.

0.000

$\mathrm{KMO}$ and Bartlett's Test of non-marketing factors

Kaiser-Meyer-Olkin Measure of Sampling

Bartlett's Test of Sphericity Approx. Chi-Square

2943.415

Df

Sig. suitability for factor analysis. Meanwhile, the Barlett's test value for both marketing factors and non-marketing factors were significant, with a value of 0.000 .

The communalities value is the squared multiple correlations for the variable using the factors as predictors, which indicates the amount of variance in each variable that is accounted for. Furthermore, the initial communalities are estimates of the variance in each variable accounted for by all components or factors. Meanwhile, the extraction communalities are estimates of the variance in each variable accounted for by the components (Santos et al, 2019). If any communalities were very low in principal components extraction, another component is needed to be extracted. However, since all communalities were valid, rotating the factors in the factor analysis was then proceeded with the factor axes around the centre of coordinates. Moreover, interpreting the factors were not that simple. Thus, a Varimax rotation method was used with values greater than one were extracted as a meaningful one, which simplified the factor structure and interpretation. Tables 4 and 5 presents the values of factor loading in factor analysis. Specifically, Table 4 indicated that the highest factor loading value for marketing factor was the product (0.900), which was 'do you think a Halal Certified product is important when buying palm oil?', followed by 'Do you think a SIRIM Certified product is important when buying palm oil?' (0.886) while the lowest value was 0.516 , which was 'do you think the brand is a major factor in purchasing palm oil?'. Meanwhile, the highest factor loading value for non-marketing factors was 0.867 which was 'are you aware of the banning of oil palm by the EU?', followed by the item 'do you think that the positive campaign may affect your decision on buying palm oil?' (0.854). Lastly, the lowest value was 0.536 for 'do you think companies should do more advertising about their product?'.

Based on the results, it was observed that in marketing factors, the halal-certified product and SIRIM labelled certification were essential components that influenced consumer preferences for palm oil available in the market in Selangor. SIRIM is an accreditation by the Department of Standards Malaysia for the Product Certification Scheme to ensure product safety and reliability to end-users. Moreover, the presence of the halal logo served to be one of the criteria for the Malay Muslim consumers in selecting or making decisions to purchase palm oil products. On the other hand, Table 5 presents the items or factor loading values for nonmarketing factors, such as quality, availability, awareness, and advertising. The highest factor loading indicated that the understanding on the banning of oil palm products might influence consumer preferences or 
Table 4. Factor loading of marketing factors

\begin{tabular}{|c|c|c|c|c|}
\hline \multirow{2}{*}{ Items } & \multicolumn{4}{|c|}{ Factor } \\
\hline & 1 & 2 & 3 & 4 \\
\hline \multicolumn{5}{|l|}{ Price } \\
\hline Do you think palm oil has a better quality than other vegetable oil? & 0.781 & & & \\
\hline Do you think the current palm oil price is acceptable or affordable? & 0.760 & & & \\
\hline Do you think palm oil is healthier than other vegetable oil? & 0.710 & & & \\
\hline Do you think the content of palm oil is more important than its price? & 0.694 & & & \\
\hline Do you think price is a major factor in purchasing palm oil? & 0.725 & & & \\
\hline Do you think price influences your judgement in purchasing palm oil? & 0.541 & & & \\
\hline \multicolumn{5}{|l|}{ Place } \\
\hline Do you think place influences your judgement in purchasing palm oil? & & 0.695 & & \\
\hline Do you think place is a major factor in purchasing palm oil? & & 0.634 & & \\
\hline Would you spend more money to buy a palm oil at a further place? & & 0.624 & & \\
\hline Do you prefer buying at a specific place or don't mind buying at other place? & & 0.806 & & \\
\hline \multicolumn{5}{|l|}{ Promotion } \\
\hline Do you think company are providing enough promotion/sale? & & & 0.553 & \\
\hline Do you think promotion/sale is a major factor in purchasing palm oil? & & & 0.809 & \\
\hline Do you think promotion/sale influences your judgement in purchasing palm oil? & & & 0.776 & \\
\hline Do you only buy certain palm oil when there is a promotion/sale? & & & 0.842 & \\
\hline Does promotion/sale interest you to buy or try new brand? & & & 0.741 & \\
\hline \multicolumn{5}{|l|}{ Product } \\
\hline Do you think brand is a major factor in purchasing palm oil? & 0.516 & & & 0.564 \\
\hline Do you think product brand influences your judgement in purchasing palm oil? & & & & 0.552 \\
\hline Would you spend more to buy higher and better quality vegetable oil? & & & & 0.563 \\
\hline Do you think a Halal Certified product is important when buying palm oil? & & & & 0.900 \\
\hline Do you think a Sirim Certified product is important when buying palm oil? & & & & 0.886 \\
\hline Do you prefer palm oil over other vegetable oil & & & & 0.704 \\
\hline Eigenvalues & 8.810 & 2.920 & 1.450 & 1.240 \\
\hline Percentage of Variance (\%) & 40.040 & 13.260 & 6.610 & 5.620 \\
\hline Cumulative percentage of variance $(\%)$ & 40.040 & 53.300 & 59.910 & 65.530 \\
\hline
\end{tabular}

purchasing decision, which was due to EU's resolution to ban PO from entering Europe (MPOC, 2017). Additionally, this resolution was the result of the Environment for Visualising Images (ENVI) Directorate, which reported that oil palm was the major contributor to deforestation (MPOC, 2017). Consequently, this resolution was seen to hamper the oil palm industry, which reduced confidence in people towards consuming palm oil (MPOC, 2017). Hence, to overcome this problem, the Malaysian government developed the "Love My Palm Oil" campaign to provide exposure to Malaysians about the benefits of palm oil and its role in preserving the environment. (MPOB, 2019).

\subsection{Multiple regression of factors affecting consumer preferences}

Table 6 presents the factors affecting consumer preferences towards palm oil using multiple regression analysis. The proportion of "variability" (measured by the sum of squares) in a data set can be defined by the coefficient of multiple determination or $\mathrm{R}^{2}$, which was accounted for by a multiple regression model (Cohen et al., 2003). Generally, the conclusion of multiple regression analysis will indicate this interpretation, while the sample squared correlation coefficient between the response variable and its corresponding predicted value from the regression model was defined by the $\mathrm{R}^{2}$ (Cohen et al., 2003). Based on this study's results, $\mathrm{R}^{2}$ was reported at a value 0.405 , which indicated that the independent variables possessed a moderate association with preferences. This link showed that each of the independent variables elaborated $40.5 \%$ of the variation, which occurred in consumer preferences.

Furthermore, the results of marketing factors or 4P's showed that product and price were the most significant factors that affected consumer preferences on palm oil at $5.0 \%$ level. This result aligned with a study that indicated that a product is an essential factor in consumer preference, whereby consumers were likely to choose higher quality product (Nguyen et al., 2015). Additionally, consumers preferred to buy products that were well known for its quality, which depended on the 
Table 5. Factor loading of non-marketing factors

\section{Items}

Factor

3

Do you think packaging is a major factor in purchasing palm oil?

0.819

Do you think packaging influence your judgement in purchasing palm oil?

0.743

Do you think labelling is important in packaging of palm oil?

0.802

Do you think content information is important in packaging of palm oil?

0.720

Do you think a Halal Certified label is important in packaging of palm oil?

0.811

Do you think a Sirim Certified label is important in packaging palm oil?

0.809

Would you buy a palm oil product that does not have any proper labelling?

0.797

Do you think quality is a major factor in purchasing palm oil?

$0.547 \quad 0.653$

Do you think quality influences your judgement in purchasing palm oil?

0.687

Do you think cheaper palm oil has lower quality than expensive one?

0.737

Do you think the quality of palm oil is more important than other factors?

0.829

Do you think that the company should improve the quality of their product?

Do you think availability is a major factor in purchasing palm oil?

0.797

Do you think availability influences your judgement in purchasing palm oil?

0.784

Would you spend some time searching for specific type of palm oil?

0.744

0.566

Would you buy any type of palm oil brand available in the market?

0.597

Do you think company should make their product more available?

0.693

Do you think awareness influences your judgement in purchasing palm oil?

0.792

Are you aware of the health benefit provided by consuming palm oil?

0.682

Are you aware of the environmental effect of producing palm oil?

0.744

Are you aware of the banning of oil palm by the European Union (EU)?

0.867

Are you aware of the "Love My Palm Oil" campaign lunch this year?

0.666

Do you think that the positive campaign may affect your decision on buying

0.854

palm oil?

0.778

Do you think that the negative campaign may affect your decision on buying palm oil?

Do you think advertising is a major factor in purchasing palm oil?

0.854

Do you think advertising influences your judgement in purchasing palm oil?

0.785

Did you know about the existence of certain palm oil product from advertising?

0.708

Does the advertising attract your interest in buying that specific palm oil?

0.738

Do you think company should do more advertising about their product?

0.536

Table 6. Factors affecting consumer preferences towards palm oil

\begin{tabular}{lccc}
\hline Marketing factors & Coefficients & Std. Error & p-value \\
\hline (Constant) & 2.627 & 0.406 & 0 \\
Product & $0.1520^{* *}$ & 0.068 & 0.028 \\
Price & $0.1530^{* *}$ & 0.075 & 0.043 \\
Place & -0.039 & 0.053 & 0.468 \\
Promotion & 0.08 & 0.055 & 0.149 \\
\hline Non-marketing factors & & & \\
\hline Packaging & -0.045 & 0.046 & 0.33 \\
Quality & $0.2110^{* *}$ & 0.082 & 0.011 \\
Availability & 0.138 & 0.074 & 0.065 \\
Awareness & -0.061 & 0.059 & 0.301 \\
Advertising & $0.1360 * *$ & 0.068 & 0.049 \\
\hline No of observations & 102 & & \\
$\mathrm{R}^{2}$ & 0.405 & & \\
\hline
\end{tabular}

** Significant at 0.05 level

Dependent variable: Consumer preference types of product and its nutritional values. Although there were a variety of new products being released in the market, and consumers were becoming more aware in selecting, purchasing, using, and consuming these products, especially vegetable oils. Moreover, the dietary shift has influenced the consumers' preferences towards higher quality food products, and as a result, they were more meticulous about the products' information provided to them.

Besides that, price was also one of the marketing factors that significantly influenced consumer preferences towards palm oil. The study revealed that majority of consumers considered price as a major consideration in purchasing palm oil which may further influence their judgement and interest in purchasing palm oil. Consumers were normally attracted to products that were worth their value of money. This finding was 
also in line with a study that indicated price was an important factor in purchasing a product compared to other factors (Taiwan, 2008). In addition, the choice of healthier vegetable oil was dependent on the price since consumers generally had preferences on higher quality products at reasonable or lower prices (Zhong and Ding, 2004). Therefore, price and product were used to eliminate or confirm choices made during purchasing of vegetable oils.

Meanwhile, the results of non-marketing factors showed that quality and advertising were the most significant factors that influenced consumer preferences on palm oil. High-quality products tend to last longer compared to their lower quality counterparts. However, it is more important in the case of vegetable oils because it is related to health and food safety (Prema, 2013). This was in line with a study that quality is another factor that may affect consumer preference as consumers perceived higher quality for higher values in terms of taste and nutritional aspects (Goyal and Singh, 2007). Additionally, the results confirmed that Halal certified product status and SIRIM label certification are important for many consumers which was exemplified through the presence of these logo on the palm oil packaging and they were willing to spend more as long as the food are assured halal and safe (Abdul et al., 2016).

Our result also indicated that advertising had a positive and significant relationship with consumer preferences towards palm oil. This is in line with other studies that indicated advertising was a major factor that determined sales and had played a part in forming consumer preferences (Hastings, 2003). Advertising was commonly done through the marketing process in order to add value to the product and was used to highlight the brands (Pahwa, 2019). Advertising can be delivered through media platforms such as television, radio, and social media. Concurrently, according to Sakthipriya and Ramesh (2016), television can be the main influencing agent that would affect consumer preferences. By understanding the effect of advertising, the manufacturers could understand major factors that influence attention of consumers to their preferred or choices of brands (Ayanwale et al., 2005). More importantly, advertising through "Love My Palm Oil" campaign may provide important information to Malaysians about the health benefits of palm oil and its role in preserving the environment and thus influence purchasing decision towards local palm oil products in the markets.

\section{Conclusion}

The study focused on the factors influencing eISSN: $2550-2166$ consumers' choice of palm oil in Shah Alam, Selangor. For future studies, a more detailed data collection as well as the inclusion of other regions or states to confirm the similarities or differences is encouraged. Moreover, further research on other internal and external factors such as knowledge, sustainability, health benefits and nutritional values on palm oil can be examined. Through proper understanding, the connection between marketing factors and non-marketing factors that affect consumer preferences towards palm oil can be observed. These results indicated that price and quality play important roles in determining preferences and willingness to pay for palm oil. Besides that, the study has shown that Malaysian consumers prefer high quality palm oil attributed to attractive advertising.

Respondents obtained information on preferences of palm oil from several channels including advertisements, retailers, television, radio and others. Hence, the strategy for stimulating a healthy lifestyle, increasing palm oil consumption, promoting health benefits of palm oil, combating negative perceptions and campaign of oil palm can be aggressively planned for successful for the near future. It is recommended that marketing campaigns be adapted and improved to more effectively influence the consumers' choice of palm oil brand as well as to better understand the benefits of palm oil and the advantages it brings to the environment, health and surroundings.

\section{Conflict of interest}

The authors declare no conflict of interest.

\section{References}

Abdul, M., Yahya, M., Kamarulzaman, S.A. and Rahman, M.M. (2016). The Perception of Malaysian Consumers on the Importance of Halal Logo in Their Purchasing Decision. IOSR Journal of Humanities and Social Science, 21(10), 8-13.

Alvi, H.M. (2016). A Manual for Selecting Sampling Technique in Research. Munich Personal RePEc Archive (MPRA) Paper No. 70218. Retrieved from MPRA website: https://mpra.ub.unimuenchen.de/70218/

Anojan, V. and Subaskaran, T. (2015). Consumer's Preference and Consumer's Buying Behavior on Soft Drinks: A Case Study in Northern Province of Sri Lanka. Global Journal of Management and Business Research, 5(2), 11-33.

Ayanwale, A.B., Alimi, T. and Ayanbimipe, M.A. (2005). The Influence of Advertising on Consumer Brand Preference. Journal of Social Sciences, 10(1), 9-16.

https:// 
doi.org/10.1080/09718923.2005.11892453

Baker, R., Brick, J.M., Bates, N.A., Battaglia, M.P., Couper, M.P., Dever, J.A., Gile, K.J. and Tourangeau, R. (2013). Summary Report of the AAPOR Task Force on Non-Probability Sampling. Journal of Survey Statistics and Methodology, 1(2), 90-143. https://doi.org/10.1093/jssam/smt008

Basiron, Y. (2007). Palm oil production through sustainable plantations. European Journal of Lipid Science and Technology, 109(4), 289-295. https:// doi.org/10.1002/ejlt.200600223

Battaglia, M.P. (2011). Nonprobability Sampling. India: SAGE Publication.

Blacket, R.B., Woodhill, J. and Mishkel, M.A. (1965). Diet, Hypercholesterolaemia and Coronary Heart Disease. The Medical Journal of Australia, 1(3), 5963. https://doi.org/10.5694/j.13265377.1965.tb71398.x

Cirera, X. and Masset, E. (2010). Income Distribution Trends and future Food Demand. Philosophical Transactions of the Royal Society, 364(1554), 28212834. https://doi.org/10.1098/rstb.2010.0164

Couper, M.P. and Bosnjak, M. (2010). Internet Surveys. In Wright, J.D. and Marsden P.V. (Eds). Handbook of Survey Research, p. 527-550. Bingley: Emerald Group Publishing Ltd.

Dhinesh, S.B. and Venkateshwaran, P. (2010). Marketing problems of edible oil industry in the state of Tamilnadu. Asian Journal of Management Research, 1, 58-65.

Etikan, I., Musa, S.A., and Alkassim, R.S. (2016). Comparison of Convenience Sampling and Purposive Sampling. American Journal of Theoretical and Applied Statistics, 5(1), 1-4. https:// doi.org/10.11648/j.ajtas.20160501.11

European Commission, DG Environment. (2018). Study on the environmental impact of palm oil consumption and on existing sustainability standards. Final Report and Appendices. Study contract No.: 07.0201/2016/743217/ETU/ENV.F3. Retrieved from file://D:/FOOD\%20RESEARCH/ palm_oil_study_kh0218208enn_new.pdf

Farrokhi, F. and Mahmoudi-Hamidabad, A. (2012). Rethinking Convenience Sampling: Defining Quality Criteria. Theory and Practice in Language Studies, 2 (4), 784-792. https://doi.org/10.4304/tpls.2.4.784792

Foley, B. (2018). Surveyqizmo. Retrieved from Alchemer website: https:/www.surveygizmo.com/ resources/blog/regression-analysis/

GeoNames. (2017). World Population Review. Retrieved from Population of Cities in Malaysia (2017):
Retrieved from World Population Review website: http://worldpopulationreview.com/countries/ malaysiapopulation/cities/

Goyal, A. and Singh, N. (2007). Consumer perception about fast food in India: An exploratory study. British Food Journal, 109(2), 182-195. https:// doi.org/10.1108/00070700710725536

Gunstone, F.D. (2002). Vegetable Oils in Food Technology: Composition, Properties and Uses. United Kingdom: Blackwell Publishing Ltd.

Gupta, R. and Jain, V.K. (2014). A study of consumer behaviour towards branded food products in urban and rural areas in India. International Journal of Management and Business Study, 4(2), 42-47.

Hasan, S.A. and Khan, M.Z. (2009). The Impact of Packaging Characteristics on Consumer Brand Preference. South Asian Journal of Management Sciences, 3(1), 1-10.

Hassan, H. and Rahman, M.S. (2012). Transformation of Hypermarket Retailing Industry in Malaysia presented at International Conference on Innovation, Management and Technology Research, Malacca, Malaysia, 2012, 513-516. https://doi.org/10.1109/ ICIMTR.2012.6236449

Hastings, G. (2003). Social marketers of the world unite; you have nothing to lose but your shame, p. 14-21. Social Marketing Quarterly, 9(4), 14-12. https:// doi.org/10.1080/716100607

Holub, B.J. (2002). Clinical nutrition: 4. Omega-3 fatty acids in cardiovascular care. Canadian Medical Association Journal, 166(5), 608-15.

Huang, K.S. and Gale, F. (2009). Food demand in China: income, quality, and nutrient effects. China Agricultural Economic Review, 1(4), 395-409. https://doi.org/10.1108/17561370910992307

IBM. (2019). KMO and Bartlett's Test. Retrieved from IBM website: https://www.ibm.com/support/ knowledgecenter/SSLVMB_26.0.0/

statistics_casestudies_project_ddita/spss/tutorials/ fac_telco_kmo_01.html.

Isik, A. and Yasar, M.F. (2015). Effects of Brand on Consumer Preferences: A study in Turkmenistan. Eurasian Journal of Business and Economics, 8(16), 139-150. https://doi.org/10.17015/ejbe.2015.016.08

Jain, A. and Meenakshi, S. (2012). Brand awareness and customer preferences for FMCG products in rural market: an empirical study on the rural market of Garhwal region. VSRD International Journal of Management and Business Research, 2(8), 434-443.

Keogh-Brown, M.R., Jensen, H.T., Basu, S. Aekplakorn, W., Cuevas, S., Dangour, A.D., Gheewala, S.H., Green, R., Joy, E.J.M., Rojroongwasinkul, N., 
Thaipraset, N., Shankar, B. and Smith, R.D. (2019). Evidence on the Magnitude of the Economic, Health and Population Effects of Palm Cooking Oil Consumption: An Integrated Modelling Approach with Thailand as A Case Study. Population Health Metrics, 17, 12. https://doi.org/10.1186/s12963-0190191-y

Lam, T., Heales, J., Hartley, N. and Hodkinson, C. (2018). Information Transparency Matters in Relation to Consumer Trust in Food Safety, presented in Australasian Conference on Information Systems, Sydney: Association for Information Systems.

Mat Dian, N.L.H., Hamid, R.A., Kanagaratnam, S., Awg Isa, R.A., Hassim, N.A.M., Ismail, N.I., Omar, Z. and Mat Sahri, M.M. Palm Oil and Palm Kernel Oil: Versatile Ingredients for Food Applications. Journal of Oil Palm Research, 29(4), 487-511. https:// doi.org/10.21894/jopr.2017.00014

MPOB, M.P. (2019). PALM OIL: Love My Palm Oil Campaign. Retrieved from MPOB, Malaysian Palm Oil Board website: http://www.mpob.gov.my/en/ news/79171-palm-oil-love-my-palm-oil-campaign-

MPOC, M.P. (2017). The implications of EU Resolution to the Malaysian Palm Oil Industry. Retrieved from MPOC, Malaysian Palm Oil Council website: http:// mpoc.org.my/the-implications-of-eu-resolution-tothe-malaysian-palm-oil-industry/

Murphy, D.J. (2014). The Future of Oil Palm as a Major Global Crop: Opportunities and Challenges. Journal of Oil Palm Research, 26, 1-24.

Naderifar, M., Goli, H. and Ghaljaie, F. (2017). Snowball Sampling: A Purposeful Method of Sampling in Qualitative Research. Strides in Development of Medical Education, 14(3), e67670. https://doi.org/10.5812/sdme.67670

Nguyen, T.N., Phan, T.T. and Vu, P.A. (2015). The Impact of Marketing Mix Elements on Food Buying Behavior: A Study of Supermarket Consumers in Vietnam. International Journal of Business and Management, 10(10), 206-215. https:// doi.org/10.5539/ijbm.v10n10p206

Nondzor, H.E., Tawiah, Y.S. and Michael, A. (2015). Consumer knowledge, perception and preference of edible oil: Evidence from Ghana. Science Journal of Business and Management, 3(1), 17-23. https:// doi.org/10.11648/j.sjbm.20150301.13

Nordin, A.B., Shariff, F.M., Balu, N. and Idris, N.A. (2012). Supply and Demand Performance for the Oils and Fats Industry in Malaysia. Oil Palm Industry Economic Journal, 12(2), 14-21.

O'Brien, R.D. (2009). Fats and Oils: Formulating and
Processing for Applications. Florida: CRC Press. https://doi.org/10.1201/9781420061673

Ohen, S.B., Umeze, G.E. and Inyang, E. (2014). Consumer Purchasing Behaviour for Fruits and Vegetables among Civil Servants in Essien Udim Local Government Area, Akwa Ibom State, Nigeria. Food Science and Quality Management, 23, 55-64.

Olivier, L. (2011). River Sampling Non-Probability Sampling in an Online Environment. Web log, November 13, 2011. Center for Information-Based Decision Making and Marketing Research. Retrieved from website: http:/lexo livier.blogspot.com/2011/11/river-sampling-nonprobabilitysampling.html.

Page, I.H., Stare, F.J., Corcoran, A.C., Pollack, H. and Wilkinson, C.F.Jr. (1957). Atherosclerosis and the fat content of the diet. Circulation, 16(2), 163-78. https://doi.org/10.1161/01.CIR.16.2.163

Pahwa, A. (2019). What Is Advertising? Advertising Objectives, Examples, and Importance. Marketing Essentials. Retrieved from Feedough website: https://www.feedough.com/what-is-advertisingadvertising-objectives-examplesimportance/

Prema, R. (2013). An Empirical Study on Brand Preference Towards Edible oil in Rural Areas with Special Reference to Coimbatore District. Indian Journal of Applied Research, 3(3), 223-227. https:// doi.org/10.15373/2249555X/MAR2013/72

Regmi, A. and Dyck, J. (2001). Effects of Urbanization on Global Food Demand. Changing Structure of Global Food Consumption and Trade, WRS-01-01, 23-30.

Sakthipriya, E. and Ramesh, L. (2016). Influence of Television Advertisement on Unhealthy Food Preferences among Children. International Journal of Science and Research, 5(9), 1098-1102.

Santos, R.O., Bartira Mendes, G., Alessandra de Castro, M., Regina Mara, F., Dirce Maria, M., Valéria Troncoso, B. (2019). Principal Component Analysis and Factor Analysis: differences and similarities in Nutritional Epidemiology application. Revista Brasileira de Epidemiologia, 22(2), E190041

Sarstedt, M. and Mooi, E. (2014). A Concise Guide to Market Research: The Process, Data, And Methods Using IBM SPSS Statistics. 2nd ed. Berlin: Springer Berlin.

Sarwade, W.K. (2011). Brand Preferences and Consumption Pattern of Edible Oils in Maharashtra State. International Conference on Economics and Finance Research, 4, 330-334.

Seng, K.W. and Ahmad, M.Y. (2017). Factors Influencing Malaysian Palm Oil Export Demand in 
Long-Run and Short Run. International Journal of Business and Management, 1(2), 204-210.

Shiratori, S. and Kinsey, J. (2011). Media Impact of Nutrition Information on Food Choice presented at Agricultural and Applied Economics Association's 2011 AAEA and NAREA Joint Annual Meeting. Pennsylvania.

Swamy, M.B., Kumar, T.A. and Rao, K.S. (2012). Buying Behaviour of Consumers Towards Instant Food Products. International Journal of Research and Computational Technology, 2(2), 1-13.

Tabachnick, B.G. and Fidell, L.S. (2001). Using multivariate statistics. 7th ed. New York: Pearson Education.

Uyanik, G.K. and Güler, N. (2013). A Study On Multiple Linear Regression Analysis. Procedia - Social and Behavioral Sciences, 106, 234-240. https:// doi.org/10.1016/j.sbspro.2013.12.027

Voicu, M.-C. (2013). Characteristics of The Consumer Preferences Research Process. Global Economic Observer, 1(1), 126-134.

Wakefield, M.A., Loken, B. and Hornik, R.C. (2010). Use of mass media campaigns to change health behaviour. The Lancet, 376(9748), 1261-1271. https://doi.org/10.1016/S0140-6736(10)60809-4

Wan Ariffin, W.N.S and Abdul Fatah, F. (2018). Evaluation of Upstream Value Chain Analysis in Oil Palm: Insights from Smallholder Farmers in West Region Malaysia. The Journal of Social Sciences Research, 4, 173-183.

Weedmark, D. (2018). Definition of Consumer Preference. Retrieved from Bizfluent website: https://bizfluent.com/info-8698883-definitionconsumerpreference.html

World Population Review. (2019). 2019 World Population by Country. Retrieved from World Population Review website: http:// worldpopulationreview.com/

Zion Market Research (2017). At 7.2\% CAGR, Global Palm Oil Market Size and Share Expected to Reach $\$ 92.84$ Billion In 2021: ZMR. Retrieved on September 4, 2019, from Globe New Wire website: https://globenewswire.com/newsrelease/2017/04/19/961940/0/en/At-7-2-CAGRGlobal-Palm-Oil-Market-Size-Shareexpected- toreach-92-84-Billion-in-2021-ZMR.html.

Zhong, F. and Ding, Y. (2004). Consumer Awareness and Response to GM Foods in Nanjing. China Rural Survey, 1, 22-27. 